\title{
The Transtheoretical Model to Assist Lifestyle Modification in Adolescents with Overweight and Obesity
}

\author{
Raquel de Melo Boff ${ }^{1}$ \\ Orcid.org/0000-0002-8625-9085 \\ Carolina Domingues Segalla ${ }^{1, *}$ \\ Orcid.org/0000-0002-5174-3109 \\ Ana Maria Pandolfo Feoli ${ }^{1}$ \\ Orcid.org/0000-0001-7685-8431 \\ Andreia da Silva Gustavo ${ }^{1}$ \\ Orcid.org/0000-0002-1128-2192 \\ Margareth da Silva Oliveira ${ }^{1}$ \\ Orcid.org/0000-0002-6490-5170
}

${ }^{1}$ Pontifical University of Rio Grande do Sul, Porto Alegre, RS, Brazil

\begin{abstract}
The prevalence of overweight and obesity in adolescents has quadrupled over the last 30 years, with significant consequences for life expectancy. The main non-pharmacological intervention for these conditions is lifestyle modification. This experience report describes an interdisciplinary intervention based on the Transtheoretical Model (TTM), delivered to a group of obese adolescents with the aim of increasing motivation for lifestyle modification, evaluating motivation to change health-related behaviors, and discuss techniques to facilitate the evolution through the stages of change. The study involved thirteen participants with a mean age of 16.32 years $(S D=1.21)$, of whom five were male and a eight, female. The purpose of this report is to describe how the processes for change can increase motivation for lifestyle change in this population. At the end of the intervention, participants showed increased motivation to exercise regularly and improve eating habits, as well as a mean overall weight loss.
\end{abstract}

Keywords: Obesity, adolescent, weight control, behavior change, interdisciplinary research

Mailing address: Av. Ipiranga, 6681, Prédio 11, sala 927, Partenon, Porto Alegre, RS, Brazil. Phone: (51) 33203500 - ramal 7749. E-mail: carolinadominguessegalla@gmail.com

Este estudo foi financiado pelo governo brasileiro por meio do Conselho Nacional de Desenvolvimento Científico e Tecnológico (CNPq) com os editais Universal 483257/2013-3 e Universal 455106/2014. Também teve financiamento do edital de Infraestrutura da Pontifícia Universidade do Rio Grande do Sul (PUCRS)/ PRAIAS (01/2014). 


\title{
O Modelo Transteórico para Auxiliar Adolescentes com Sobrepeso e Obesidade a Modificar Estilo de Vida
}

\begin{abstract}
Resumo
O número de adolescentes com sobrepeso e obesidade quadriplicou nos últimos trinta anos, gerando possível redução na sobrevida. $\mathrm{O}$ tratamento não medicamentoso está relacionado à mudança de estilo de vida, visando a redução de peso. O presente relato de experiência visa descrever uma intervenção interdisciplinar grupal baseada no Modelo Transteórico de Mudança (MTT) para motivar adolescentes com sobrepeso e obesidade a modificar o estilo de vida, avaliar a motivação para a modificação de diferentes comportamentos relacionados à saúde, e explanar estratégias que facilitam a evolução nos estágios de mudança. Participaram deste estudo 13 jovens, com idade média de 16,32 anos $(D P=1,21)$, sendo cinco do sexo masculino e oito do feminino. Este relato procura apresentar a forma que os processos de mudança podem contribuir no aumento da motivação para mudança do estilo de vida. Ao final da intervenção o grupo apresentou aumento na motivação para praticar exercício físico e regular hábitos alimentares, e perda média de peso.
\end{abstract}

Palavras-chave: Obesidade, adolescente, controle de peso, modificação do comportamento, pesquisa interdisciplinar.

\section{El Modelo Transteórico para Ayudar Adolescentes con Sobrepeso y Obesidad a Cambiar su Estilo de Vida}

\section{Resumen}

El número de adolescentes con sobrepeso y obesidad cuadruplicó en los últimos treinta años y las consecuencias de esa condición pueden llegar a ser la reducción de la sobrevida. El tratamiento sin medicinas se hace por medio del cambio de estilo de vida enfocado a la reducción de peso. El informe expone una intervención interdisciplinar en grupo basada en el Modelo Transteórico (MTT) para motivar adolescentes con sobrepeso y obesidad a modificar su estilo de vida, evaluar su motivación para la modificación de comportamientos relacionados a la salud, y explicar estrategias que facilitan la evolución en las etapas de cambio. En este estudio participaron 13 jóvenes, con edad mediana $=16,32(D E=1,21)$, cinco del sexo masculino y ocho del femenino. Este informe busca demonstrar la forma que los procesos de cambio pueden estimular el aumento de motivación para el cambio del estilo de vida. Al final de la intervención el grupo presentó aumento de la motivación para practicar ejercicio físico regularmente y mejorar hábitos alimenticios, y perdida media del peso inicial.

Palabras clave: Obesidad, adolescente, control de peso, cambio de comportamiento, investigación interdisciplinaria.

The growing prevalence of overweight and obesity, both of which are considered chronic conditions, in populations of children and adolescents, has brought these issues into the focus of health promotion efforts (World Health Organization [WHO], 2016). According to international estimates published by the World Obesity Federation (WOF, 2016), 10\% of all individuals between the ages of 5 and 17 years were overweight, while 2-3\% were obese as of 2004. Cur- rently, in the American continent, this figure is estimated at $30 \%$ (WOF, 2016). In Brazil, the 2008-2009 Family Budget Survey (Pesquisa de Orçamento Familiar [POF]) has reported similarly alarming trends for these data over the past 30 years: the prevalence of overweight in adolescents aged 10 to 19 has risen from 3.7 to $21.7 \%$ in males and 7.6 to $19.4 \%$ in females, while that of obesity has gone from 0.4 to $5.9 \%$ in males and 0.7 to $4 \%$ in females (Instituto Brasileiro de 
Geografia e Estatistica [IBGE], 2010). According to the ERICA (Estilo de vida e Risco Cardiovascular em Adolescentes) multicenter study, $28.4 \%$ of obese adolescents already exhibit arterial hypertension, while $20 \%$ have hypercholesterolemia, $7.8 \%$ have high triglycerides and 46.8\%, low HDL - High Density Lipoproteins (Faria-Neto et al., 2016), with the prevalence of metabolic syndrome in the sample estimated at $2.6 \%$ (Kuschnir et al., 2016). Given the fivefold increase in the risk of adult obesity identified in obese adolescents, and the role of obesity as a predictor of early cardiovascular events, this condition is likely to contribute to a decrease in the life expectancy of this population (Simmonds, Llewellyn, Owen, \& Woolacott, 2016).

Weight loss through lifestyle interventions involving changes in diet and physical activity are known to have an especially positive effect on health (Ford, Hunt, Cooper, \& Shield, 2010). However, adherence to weight loss programs among adolescents is notoriously low, with dropout rates of approximately $50 \%$, and only $5 \%$ of individuals maintaining their weight loss after interventions (França, Sahade, Nunes, \& Adan, 2013). Health responsibility has been identified as one of the main predictors of treatment adherence in this population (Sousa, Gaspar, Fonseca, \& Gaspar, 2016).

Lifestyle modification is a complex process, especially in adolescence, suggesting that this population may require a specific set of intervention strategies in addition to interdisciplinary care (Spear et al., 2007). Treatment programs should also have a multi-domain structure, focusing on issues such as nutritional education, physical education, psychological support and family involvement, while using technological resources, as well as age-appropriate language (Boff, Liboni, Batista, de Souza, \& Oliveira, 2016).

As a result of these observations, the Transtheoretical Model (TTM) has been increasingly adopted by health professionals as an intervention strategy in lifestyle modification programs for weight loss in adolescents, and has produced positive results, with especially beneficial effects on calorie intake and anthropometric measures (Han, Gabriel, \& Kohl, 2015; Mostafavi,
Ghofranipour, Feizi, \& Pirzadeh, 2015; Prochaska, Norcross, Fowler, Follick, \& Abrams, 1992). The TTM was first described by Prochaska and DiClemente (1983), who analyzed and compared 29 different types of psychotherapy with a focus on behavioral change, and postulated four dimensions which mediate these modifications over time: the stages of readiness to change, processes of change, markers of change and the context of change (Prochaska, DiClemente, \& Norcross, 1992).

The stages of change correspond to the temporal dimension of change, and therefore describe a number of thoughts and behaviors which influence treatment adherence. The stages include: precontemplation, contemplation, preparation, action and maintenance, and describe when people change (Prochaska, DiClemente et al., 1992). The stages overlap with processes of change, which shed light on how people change, or move between different stages, in patterns which may be unique and vary from person to person. The authors describe ten processes of change, five of which are cognitive/experiential - consciousness raising, dramatic relief, environmental reevaluation, self-reevaluation and social liberation - while the remaining five are behavioral - stimulus control, counterconditioning, reinforcement management, self-liberation and helping relationships. Self-efficacy and decisional balance are the main markers of adherence to a healthy lifestyle (Mostafavi et al., 2015), while the context of change includes both the internal environment - personality, life history and cognitive resources - and the external environment - interpersonal relationships and the social context (Velicer, DiClemente, Rossi, \& Prochaska, 1996).

Current recommendations for the care of obese individuals, issued by the Brazilian Ministry of Health in the form of Basic Health Charter (Caderno de Atenção Básica [CAB]) n. 38, specifically mention the TTM, and the need to evaluate and encourage patient progress through the stages of change (Ministério da Saúde, 2014). Nevertheless, no studies in the Brazilian literature have sought to describe how these concepts can be implemented in clinical practice. As such, 
the aim of this article was to describe an intervention based on the TTM for the modification of diet and exercise in a group of adolescents with overweight or obesity. This report addresses the strategies used to encourage the processes of change, promote motivation and encourage progress through the different stages.

\section{Method}

\section{Data Collection}

The study involved a group of 13 adolescents, five of whom were male while eight were female. Participants were recruited through local print and online media. Potential participants, together with their parents, were invited to a preliminary interview with an interdisciplinary team, in which the goals of the study were presented, and individuals were screened for the following inclusion criteria: age between 15 and 18 years; overweight or obesity (BMI percentile $\geq 85$ ); and exclusion criteria: absolute contraindication to exercise, severe psychiatric illness and/or significant cognitive impairment, type I diabetes mellitus, pregnancy and unavailability to participate in the program. After the screening process, consent and assent forms were read to parents and participants, respectively, and all documents were signed prior to data collection.

Program meetings were conducted at the Pontifícia Universidade Católica do Rio Grande do Sul (PUCRS) by an interdisciplinary team, formed by members of the Department of Nutrition, Nursing and Physical Therapy (FAENFI) and the school of Psychology. The intervention was coordinated by a psychologist with experience in the TTM, who drew on the contributions of health professionals to integrate knowledge from different domains and elicit the processes of change. Over the course of three months, 12 weekly meetings with a duration of $1 \mathrm{~h} 30 \mathrm{~min}$ were held with the adolescents, in addition to two meetings with family members only, at the beginning and end of the program, in order to strengthen family support. All meetings were audio recorded, with the consent of participants, for later transcription.

\section{Intervention}

The intervention consisted of a structured protocol based on the Group Treatment for Substance Abuse: A Stages of Change Therapy Manual (Velasquez, Mauer, Crouch, \& DiClemente 2001). The original version of the program consisted of 29 sessions with a focus on abstinence from licit and illicit drugs. The current intervention was adapted under the supervision of one of the founders of this approach, Carlo DiClemente, for the modification of eating habits and initiation of physical exercise (Ludwig, 2012). Intervention strategies, originally destined for adults, were adapted for use with adolescents through modifications in their language and procedures (Ribeiro et al., 2016).

The intervention for adolescents consisted of a 12-session protocol, whose first six meetings focused on the initial stages of readiness for change - precontemplation, contemplation and preparation. Evolution through these stages was encouraged using strategies for the stimulation of cognitive/experiential processes. The last six meetings sought to stimulate behavioral processes, which are important for action and maintenance. As proposed in the original protocol, the health professionals who conducted the meetings used motivational strategies to stimulate progress through different stages (Velasquez et al., 2001).

All meetings followed a similar structure. In the first hour, the topics described in the protocol (Ribeiro et al., 2016) were discussed with the help of supporting materials and activities, while in the final half hour, participants were invited to take part in a physical activity, so as to learn about different types of exercise. This was achieved using resources such as motion based videogames, music and the facilities available at the university. Two additional meetings were organized for the families of participants in order to explain the importance of keeping the adolescents motivated.

\section{Instruments}

The intervention was delivered in a closed group format with weekly meetings, which were 
audio-recorded with the consent of participants and legal guardians, for later transcription and analysis. The aim of this process was to understand the progression of the behavioral change from the experience of participants. Readiness to enact lifestyle changes was examined using Readiness Rulers. This instrument was originally developed by Velasquez et al. (2001), and consisted of two questions pertaining to exercise frequency and intensity, as well as nine questions about eating habits. For each item, the respondent was asked to indicate, on an analogue scale ranging from 0 to 10 , the extent to which they were ready to change the behavior at that particular point in time.

Weight was measured before and after the intervention using a calibrated Cauduro ${ }^{\circledR}$ scale, with a $160 \mathrm{~kg}$ capacity. Participants were weighed barefoot with as little clothing as possible. Height was measured using a stadiometer (Sunny ${ }^{\circledR}$ ). These values were used to calculate the Body Mass Index (BMI) of each participant based on the weight/height ${ }^{2}$ ratio (WHO, 2000).

\section{Data Analysis}

The elicitation of the processes of change described by the TTM was evaluated from a clinical practice perspective, through an experience report of the observation of all sessions of an interdisciplinary intervention for adolescents with overweight and obesity. The integration of theory and practice was aided by quotes from the participants illustrating the progression and movement of adolescents through the processes of change.

\section{Ethical Considerations}

This study is part of a larger project, titled "Effect of interdisciplinary interventions with a motivational approach on lifestyle modification in adolescents with overweight and obesity (MERC-IV)", which was approved by the PUCRS Research Ethics Committee in 2014 (CAAE: 36209814.6/0000.5336). The MERCIV is a randomized clinical trial, in which participants were assigned to one of two conditions: a control (CG) or intervention group (IG), both conducted by health professionals from the pre- viously mentioned departments, as well as a volunteer with a background in physical education, who was consulted on matters pertaining to physical exercise. The present report will focus on the experience of conducting one of the IG (Ribeiro et al., 2016).

\section{Results}

\section{Participant Characteristics}

Participants had a mean age of 16.32 years $(S D=1.21)$, and weighed a mean of $97.71 \mathrm{~kg}$ $(S D=22.43)$ prior to the intervention. Three were first-year university students, eight were in high school, while two were approaching the end of middle school. Only one participant was employed. All participants had previously tried to establish an exercise regimen, but gave up after one to three months. They had also tried to follow a diet, but stopped after two weeks to a month.

\section{Experience Report}

The authors of the TTM emphasize the importance of stimulating the processes of change according to the individual's stage of readiness (Prochaska, DiClemente et al., 1992). In present study, adolescents appeared to have entered the group in the early stages of readiness. Therefore, this report was structured into topics, to explore the techniques used and the developments observed in the context of each process of change, as well as the sessions in which the processes took place. Since processes do not unfold in a linear fashion, some of the topics combine multiple processes which were seen to co-occur.

\section{Consciousness Raising}

This process is related to the awareness of the effects of a given behavior on a person's health (Prochaska, DiClemente et al., 1992). In the first meeting, in addition to working on the group contract, participants were provided with information on the consequences of obesity. This was achieved by returning the results of the clinical examinations performed by participants before the intervention, which investigated 
cholesterol levels, triglycerides, fasting glucose, glycated hemoglobin, c-reactive protein, vitamin $\mathrm{D}$ and cardiorespiratory capacity.

To help them interpret the clinical findings, individuals were given information on reference values, cutoff points, as well as the impact of nutrition and a sedentary lifestyle on health. An anatomical model of atherosclerosis was shown to participants, who were also given a tablet computer with the 3D Heart app, which they could use to learn about the heart. Participant E. (age 16) was surprised to find that cardiovascular diseases are common among adolescents: "So this means I could just drop dead!". Consciousness raising techniques are often met with this type of reaction, since people may not have had access to accurate information regarding their condition prior to the intervention.

Another important aspect of consciousness raising is providing information on the treatment that is being offered. Prior to learning how the TTM-based intervention would work, adolescents were asked about their reasons for taking part in the program. Participant G. (age 16) answered:

my mom put me in the car, said I was going to my grandmother's house, and all of a sudden we were here at PUCRS, so I thought, did my grandmother move?! But then my mom said I was going to be in a program to lose weight because I was too fat.

Another girl, A. (age 17), replied: "I'm in the MERC [program] because my dad gives me 100 reais every time I come here".

These reports suggest that most adolescents were in the precontemplation or contemplation stages at the start of the program, seemingly resistant and wary of treatment. Health professionals therefore relied on the "motivational spirit" to decrease resistance and ambivalence and promote motivation, as suggested by Velasquez et al. (2001). As such, in addition to listening empathically to the adolescents' external reasons for participating in the program, coordinators also tried to elicit intrinsic motivation. Participants were told of the stages of readiness to change, and asked to identify the stage in which they found themselves with regards to eating habits and increased physical activity. Participant $M$. (age 17) believed he was in the action stage with regards to physical exercise: "for exercise I think I'm in action, since I play American football and train three times a week, but my problem is with food... If I were thinner I would have participated in the national championship".

Although consciousness raising was mostly emphasized in the first group meeting, this process continued to develop over the course of the program, through techniques which provided information on eating behaviors and physical exercise, as well as the provision of alternative choices to reinforce the process of change of each individual.

\section{Dramatic Relief, Self-Reevaluation and Environmental Reevaluation}

The second meeting focused on dramatic relief and self-reassessment. The process of dramatic relief deals with the emotional experiences associated with weight (Prochaska, Norcross et al., 1992). This process was encouraged by raising awareness of the impact of certain foods and physical activities on health, which included the introduction of the evil TRIAD: salt, sugar and fat (Associação Brasileira para o Estudo da Obesidade, 2016). Participants were also shown the age-adjusted reference values for physical activity set by the Brazilian Society of Exercise and Sports Medicine (2016).

After providing this information, coordinators asked participants to think about the concerns that people around them might have with regards to their behavior. In response to this request, most adolescents mentioned parental concerns, which were often expressed in an aggressive manner: "As if yelling is going to change anything! I know I only eat junk, but yelling isn't going to fix that" (G., age 17); "They have no patience, they think we are fat because we want to be fat. If I could choose, I would be like Gisele" (B., age 17). "Going to the gym with my mom was hell. She kept peeking at me through the equipment to make sure I was really exercising" (G., age 18). The aim of this strategy was to evaluate the ways in which others express their concern for participants, and its end result was the identification of several negative emotional experiences in the context of adolescents' families. 
When asked what they thought of these concerns and inquired as to their own experiences with weight, adolescents described how clothes shopping -- which should be a pleasurable experience - was often a cause for sadness and anger: "There are no clothes my size and we always resort to black. I'm sick and tired of having a closet full of black clothes" (E., age 16).

I can never buy those boots that go over the knee. I see those people with thigh-high boots and think: how did that fit? Those barely fit my arm. Of course I would like to go to parties in boots and shorts. (A., age 17) "My foot is fat and I have to wear a size 45. It's really hard to find tennis shoes" (L., age 16). Participants also mentioned sadness, fear and shame due to bullying at school and other social settings: "There was lots of teasing at school, but not anymore... nowadays, no one would be crazy enough to mess with someone my size" ( $\mathrm{P}$., age 16); "You know what's worse? When they call you chubby... I get so angry! Yes I'm fat, not chubby, so what? I didn't ask anyone to buy me food, $f^{* * *}$ off" (A., age 17); "Imagine being in the national finals for the American football [championship] and having a guy tell you: Yeah, man, it's not going to work, you're overweight and it could hurt the team" (M., age 17). Adolescents' negative weight-related experiences were often associated with the issues that typically emerge in this developmental stage, and as such, were quite distinct from the issues that worried their parents. While the concerns of family members were mostly health-related, adolescents were worried about looks and social acceptance. To push individuals toward action, health professionals should emphasize intrinsic reasons for change, understanding and exploring them in order to foster optimism and hope (DiClemente, 2015).

The process of self reevaluation involves an assessment of the conflicts between personal values and current behaviors (Velasquez, et al., 2001). After reflecting on the emotional experiences they had suffered as a result of being overweight, adolescents were able to identify the things they felt were most valuable. As such, in the third meeting, participants were asked to focus on the behaviors that prevented their weight loss and describe the way these behaviors conflicted with their values. The group talked about family and the constant arguments over eating habits: "my mom never leaves me alone" (L., age 16), "my girlfriend nags me every time I buy soda" (J., age 17). There was also unanimous concern about the inability to participate in activities with other adolescents due to weightrelated issues:

One time I wanted to go on a zip line, but I couldn't because there was a weight limit. I cried a lot at home afterwards, because at the time you think, well that's too bad, but later you get angry at yourself and want to punch everything you see, and all you can do is eat a tub of ice cream. (A., age 16)

To which another group member replied: "it's a vicious circle, you are hurt then eat, get angry at yourself and eat, and never lose weight" (A., age 17);

in summer I go to the park and see all those people on the slackline, but how would it look if I tried it? Of course it wouldn't work, the thing would go all the way down to the ground. I would never balance on it. (E., age 16)

Self-esteem was the main factor affected by weight: "they call me minion, shorty, smurf... Of course, I'm 1.60m tall and chubby, but I didn't want to be like that" (E., age 16); "they call me Panda, because when I was seven years old I was like a little ball, and when I ran it looked like a panda running. Now I'm used to it" (P., age 16); "When they suggest we go somewhere where I would have to wear a bikini I tell them: are you crazy?! I look at my legs and decide not to go" (A., age 17); "Water parks are always a problem because I am always above the weight limit, and I get angry because I obviously wanted to go on the rides" (J., age 16). Self-reassessment is an important part of the contemplation stage, as it helps adolescents identify the "vicious circle" caused by unhealthy food choices and sedentary habits, which also keeps them away from the things in their lives which they consider important.

The processes of change do not follow a linear trajectory. In some cases, they may occur simultaneously, as in the case of self- and 
environmental reassessment. When reevaluating the consequences of one's own behaviors, the individual may also evaluate the negative impact their condition may have on their surroundings. This is known as environmental reassessment, and is often a potent source of motivation for change (Velasquez et al., 2001). Being overweight can have a direct impact on family relationships: "My girlfriend always nags me... Then we fight and she cries" (J., age 17); "My mom signed up to my gym just to see if I'm really exercising, but she can't exercise because she has heart problems, so I feel bad for her" (G., 17 years). In the context of weight-loss interventions, environmental reassessment has proved to be a weaker predictor of outcome than other processes of change, as discussed by Prochaska, Norcross et al. (1992). When validating a Spanish instrument for the assessment of processes of change, Andrés, Saldanha and Gómez-Benito (2011), found that dramatic relief, self reassessment, social liberation and self-liberation are the main contributors to weight loss behaviors.

The present intervention corroborates previous findings in that the family environment was the only setting which participants felt was affected by their behavior. After all, being overweight, eating unhealthy foods and failing to engage in physical activity is more detrimental to the individual than to their surroundings.

\section{Self-Liberation, Social Liberation and Helping Relationships}

DiClemente (2006) defines self-liberation as the commitment to change by setting clear and realistic goals. Since goal-setting is part of the planning stage, this process was specifically discussed in session six, in which nurses used an interactive technique to introduce the concept of self-care. In the activity, participants were shown several loaves of bread and asked whether they would eat them. However, some items had been injected with food coloring, which was only visible upon cutting into the loaf. After seeing the stains on the inside of the bread, participants were asked to reflect on the hidden consequences of their behaviors in the long run. The concept of self-care was discussed, and participants were asked to write about the self-care behaviors they might be able to perform.

This was an important moment for participants, most of which had difficulty setting concrete goals, and listed objectives such as "eating healthy". There was a need to specify the behaviors which could get them close to these goals, as well as identify any possible obstacles in their path. They were encouraged to list behaviors which were both realistic and concrete, resulting in goals such as: "getting off the bus one stop before my house and walking the rest of the way", "drinking soda only on weekends", and "signing up to a gym" all of which reflect commitment to the idea of losing weight. Participant R. (age 18) said she "would stop eating fatty foods, but one of the obstacles to that would be my own family, especially mom, who makes lots of deep-fried food". Other participants also identified friends and relatives as significant obstacles to weightloss goals, since both groups have a strong influence on eating behaviors (Dalcastagné, Ranucci, Nascimento, \& Liberalli, 2008).

Social liberation is often discussed in combination with self-liberation, since it deals with identifying and creating alternatives to promote change in social situations (DiClemente, 2006). Though family members may wish the individual would lose weight, any changes in their habits will affect the entire family system and often result in discomfort. This was evident in meetings with the family, in which a mother said: "my daughter is so annoying now that she comes here. She wants to read everything at the supermarket, choose the food, and if I dare give a juice box to the little one, she scolds me".

Social deliberation techniques can also be used by health professionals to help adolescents develop assertiveness, a necessary skill when dealing with friends and relatives. This was achieved using role play, which allowed adolescents to practice saying "no" when offered certain foods, even when faced with arguments aimed at persuading them to eat. The nutritionist provided adolescents with replicas of food items, and asked them to play the role of someone offering as well as someone refusing the food. When role-playing the first scenario, one partici- 
pant (L., age 16) said: "eat this piece, or else it's going into the trash, and there are so many children starving in Africa". According to the participant, this was the argument his grandmother used to "stuff him full of food". Another method used to identify sources of reinforcement to change in the environment involved encouraging adolescents to use assertiveness in order to organize social outings to locations which provided healthier eating alternatives: "so like, everyone went to eat fast food, and I said, then let's go to the mall, because there I can choose something else" (E., age 16), and engage in physical exercise: "my neighbor walks her dog everyday, and Inever even really talked to her. Then we started talking and I started walking with them and my dog, too" (A., age 17).

Changes to social settings may also arise as a result of helping relationships. Identifying these relationships is another important aspect of working with adolescents, since they may offer support, care and acceptance to the person going through change (Velasquez et al., 2001). This was discussed in the tenth meeting, in an attempt to identify sources of support which would help the change to continue even after the intervention ended. The activity used in this meeting consisted of the creation of a virtual poster with images of people or services which were helping participants change. This was achieved using tablet computers and the Internet. Group coordinators were surprised to see that adolescents collected real pictures from their social networks in order to set up the posters, looking for pictures of close friends, boyfriends, girlfriends, pets and relatives. G. (age 17) brought a picture of her bird and said that when she felt anxious and wanted to eat, she would play with him. All her negative feelings would go away, and she would manage not to eat. Another participant brought a picture of a man wearing a football uniform, and said his trainer was the person who encouraged him the most. This was one of the most important moments in the intervention, since it showed the team that participants would not feel helpless or alone as they sought continuing change, with their helping relationships acting as a support system.

This type of support is essential for future decision-making, since participants will often be faced with multiple simultaneous alternatives, whose costs and benefits will have to be analyzed in the short, medium and long term. In these situations, the support network may protect against impulsive decisions in the context of unhealthy eating habits, and prevent participants from giving up physical exercise. In addition to helping relationships, behavioral processes also play an important role in decision-making for continued change.

\section{Stimulus Control, Counterconditioning and Reinforcement Management}

Maintaining the behavior change is as difficult as initiating it: most people can start a diet or an exercise regimen, but they will also give up over time (França et al., 2013). Staying active or transforming change into a habit requires constant self-monitoring. Therefore, behavioral processes such as stimulus control, counterconditioning and reinforcement management are essential for weight-loss interventions. These processes of change were discussed simultaneously from meetings 7-12.

Stimulus control involves modifying situations considered "triggers" for relapse (DiClemente, 2006). In the context of lifestyle modification, triggers are associated with situations which tempt the individual to leave the diet or stop exercising. To identify these situations, the adolescents were invited to take part in an activity. Participants were asked to brainstorm and write down on post-it notes any tempting situation they believed may be an obstacle to a healthy lifestyle. Triggers related to eating behaviors included having non-diet foods at home; going to the supermarket when hungry; going to parties; weekends and holidays; menstrual periods; experiencing strong negative emotions. Obstacles to engaging in physical activity included laziness; muscle pain; bad weather; invitations for social events which take place at the time they would usually exercise; homework. All post-its were glued to a poster board. Participants were then invited to cover them with additional postit notes containing alternative ways to deal with the situations described.

The aim of this activity was to work on counterconditioning, or the substitution of healthy 
behaviors for unhealthy ones when trigger situations cannot be avoided (Velasquez et al., 2001). It is not possible to refuse all party invitations, or prevent individuals from eating tempting foods in the presence of others on a diet. Participants were once again invited to brainstorm about ways they had dealt with these situations in the past, as well as methods to deal with them in the future. Several creative alternatives were identified, such as: eating something healthy at home before going to a party; eating fruit with honey or cinnamon when one felt like eating sweets; listening to music, rather than eating, when one is sad; being assertive in parties and weekends in order to stay on the diet; exercising despite feeling lazy; using stairs instead of the elevator.

Another technique used in the meetings to work on counterconditioning was the temptations table. In the seventh meeting, participants were introduced to the concept of classical conditioning, in which a neutral stimulus may come to evoke innate physiological responses when presented simultaneously with an unconditioned stimulus such as food (Queiroz de Medeiros, Pedrosa, \& Yamamoto, 2016). The aim of this technique was to set up a table with realistic replicas of food enjoyed by the adolescents, and invite them to experience the reactions they would usually have when seeing these items. Their first reaction when learning of the activity was to ask the research team whether the theme of the meeting was "torture." They discussed their difficulties in controlling the desire to eat, which manifested as salivation and memories of smell and taste evoked by the sight of food. The neural mechanisms associated with food cravings are similar to those observed in substance dependence. Dopamine levels increase after food consumption, and over time, this response becomes conditioned to the anticipation of eating, and must therefore be subjected to extinction (Temple, 2016). After the exposure technique, adolescents learned about the difference between physiological and psychological hunger, and verified whether their previous responses to the food had remained or disappeared. The group concluded that craving may be transient, and that controlling intrusive thoughts is crucial for this process.
The control of behaviors and thoughts in these situations can be effectively achieved through self-monitoring, as has been widely demonstrated in the literature (Boff et al., 2016). However, it must be preceded by attention to the context, in order to monitor it and decide whether to change it. Therefore, a mindful eating technique was introduced to allow participants to practice awareness while eating (Daly, Pace, Berg, Menon, \& Szalacha, 2016).

Reinforcement management deals with the rewards associated with positive behavior changes, either in the form of external contingencies or benefits associated with lifestyle modification (DiClemente, 2006). The last two meetings involved a discussion of the positive aspects which participants could already observe as a result of their ongoing lifestyle modifications. Some said they lost weight, while others found they could purchase smaller clothing sizes and practice sports at school without feeling tired. In the final meeting, health professionals gave the adolescents cards describing each of their achievements over the course of the threemonth program, as an incentive for continued change.

At the end of the intervention, participants showed an increase in their motivation for engaging in 30 minutes of aerobic physical exercise on a daily basis, as measured by the readiness ruler. Seven participants were in the action/maintenance stages with regards to this outcome, while four were in the preparation stage. Improvements were also observed in participants' eating habits, with nine individuals finding themselves in the action/maintenance stages with regards to fruit and vegetable intake, and four in the preparation stage for this particular outcome. Even behaviors which are difficult to modify in adolescence, such as sugar and fat consumption, appeared to show improvements at the end of the program, with most participants $(n=10)$ finding themselves in preparation for change.

Eight participants also exhibited weight loss, while the mean change in weight after the intervention calculated as a percentage of preintervention weight was estimated at $1 \%$. These results suggest that strategies to stimulate the 
processes of change can increase motivation for the behavior changes required for weight loss in adolescents.

\section{Discussion}

The present study corroborates the existing literature on the importance of interdisciplinary work (Boff et al., 2016) based on unified strategies which guide practice in each professional discipline. The limitations of the present study include the need to identify which of the 10 cognitive/experiential and behavioral processes contributed the most to behavior change in this population. Additionally, from a theoretical standpoint, participants should ideally be in a similar stage of readiness for change at the start of the intervention. According to the literature, the motivational stage should determine which processes of change are elicited, which is often referred to as "doing the right thing at the right time" (Prochaska, DiClemente et al., 1992). Although most participants were in the precontemplation or contemplation stages for changing their diets, some were in more advanced stages for exercise-related behaviors. A greater uniformity in motivational stages may have benefited the group, since the processes of change elicited would have been facilitated and reinforced by participants' attitudes.

Another important limitation of the present study was having too few meetings with family members. The family was found to play a crucial role in lifestyle modification, be it by reinforcing or hindering the behavior change. Obese parents are $80 \%$ more likely to have obese children, both for genetic reasons, and due to poor dietary and exercise habits (Dalcastagné et al., 2008). The family also influences individual concerns with regards to one's body, contributing to the development of body image and the self-concept (Helfert \& Warschburger, 2011).

Since the present study followed a research protocol, coordinators received specific instructions prior to each meeting, and several variables were controlled. Nevertheless, this report allows for interesting reflections on the rigidity of some research and treatment protocols, and its poten- tially negative impact on adherence. The strategies used when working with adolescents must be flexible and adapted to their developmental stage, and professionals must empathize with the issues that emerge over the course of adolescence. Bonding with participants is as important as mastering the intervention techniques to ensure that the work is successful. When working with behavior change research, individuals must find balance in their methodological rigidity, in order to refrain from compromising the research process, while also maintaining proximity to their object of study (Boff \& Strey, 2014).

These reflections may contribute to the ongoing MERC-IV study as well as future projects which focus on a similar issue. The relevance of this experience report lies precisely in its contribution to the comprehension of findings produced by its parent project, which aims to subject the intervention described herein to empirical testing. We suggest that researchers dedicate additional effort to similar qualitative studies of interventions for obesity in adolescents. Though the literature boasts a large number of randomized clinical trials on the subject, few studies have described the way the interventions have taken place. The intersection of effectiveness studies and experience reports may provide the empirical basis for new intervention models to be implemented by the public health system.

\section{Authors' Contributions}

Substantial contribution in the concept and design of the study: Raquel de Melo Boff e Carolina Domingues Segalla

Contribution to data collection: Raquel de Melo Boff e Carolina Domingues Segalla

Contribution to data analysis and interpretation: Raquel de Melo Boff e Carolina Domingues Segalla

Contribution to manuscript preparation: Raquel de Melo Boff e Carolina Domingues Segalla

Contribution to critical revision, adding intelectual content: Raquel de Melo Boff, Carolina Domingues Segalla, Ana Maria Pandolfo Feoli, Andreia Gustavo, e Margareth da Silva Oliveira. 


\section{Conflicts of interest}

The authors declare that they have no conflict of interest related to the publication of this manuscript.

\section{References}

Andrés, A., Saldaña, C., \& Gómez-Benito, J. (2011). The transtheoretical model in weight management: Validation of the processes of change questionnaire. Obesity Facts, 4(6), 433-442. doi: $10.1159 / 000335135$

Associação Brasileira para o Estudo da Obesidade. (2016). Diretrizes Brasileiras da Obesidade [Brazilian Obesity Guidelines] (4rd ed.). São Paulo, SP: Author. Retrieved from http://www.abeso. org.br/uploads/downloads/92/57fccc403e 5 da. pdf

Boff, R. M., \& Strey, M. N. (2014). A psicologia clínica é filha do positivismo? [Does Clinical Psychology stem from positivism?]. In K. C. Kohn, L. R. S. Pinheiro, \& M. N. Strey (Eds.), (Dez)Ensaios Temáticos: Construções de teses em psicologia. Erechim, RS: Edifapes.

Boff, R. M., Liboni, R. P., Batista, I. P., de Souza, L. H., \& Oliveira, M. D. (2016). Weight loss interventions for overweight and obese adolescents: A systematic review. Eating Weight Disorders Journal, 22(2), 211-219. doi: 10.1007/s40519016-0309-1

Brazilian Society of Exercise and Sports. (2016). Physical Activity in childhood and adolescence. São Paulo, SP: Author. Retrieved from http:// www.medicinadoesporte.com/SBME_PosicionamentoOficial_1998_AtividadeFisica

Dalcastagné, J. M. A., Ranucci, J. M. A., Nascimento, M. A., \& Liberalli, R. (2008). A influência dos pais no estilo de vida dos filhos e sua relação com a obesidade infantil [The parents' influence on children's lifestyle and its relationship with childhood obesity]. Revista Brasileira de Obesidade, Nutrição e Emagrecimento, 2(7), 44-52. Retrieved from http://www.rbone.com.br/index. php/rbone/article/view/67

Daly, P., Pace, T., Berg, J., Menon, U., \& Szalacha, L. A. (2016). A mindful eating intervention: A theory-guided randomized anti-obesity feasibility study with adolescent Latino females. Complementar Therapies in Medicine, 28, 22-28. doi: 10.1016/j.ctim.2016.07.006
DiClemente, C. C. (2006). The process of human intention behavior change. In C. C. DiClemente (Ed.), Addiction and Change (pp. 22-43). New York: The Guilford Press.

DiClemente, C. C. (2015). Change is process not a product: Reflections on pieces to the puzzle. Substance Use \& Misuse, 50(8-9), 1225-1228. doi: $10.3109 / 10826084.1042338$

Faria-Neto, J. R., Bento, V. F. R., Baena, C. P., Olandoski, M., Gonçalves, L. G. O., Abreu, G. A., ...Bloch, K. V. (2016). ERICA: Prevalência de dislipidemia em adolescentes brasileiros [ERICA: Prevalence of Dyslipidemia in Brazilian adolescents]. Revista de Saúde Pública, 50(1), 10. doi: https://dx.doi.org/10.1590/S015188787.2016050006723

Ford, A. L., Hunt, L. P., Cooper, A., \& Shield, J. P. (2010). What reduction in BMI SDS is required in obese adolescents to improve body composition and cardiometabolic health? Archives of Disease in Childhood, 95(4), 256-261. doi: 10.1136/adc.2009.165340

França, S. L., Sahade, V., Nunes, M., \& Adan, L. F. (2013). Adherence to nutritional therapy in obese adolescents; a review. Nutrition Hospital, 28(4), 988-998. doi: 10.3305/nh.2013.28.4.6481

Han, H., Gabriel, K. P., \& Kohl, H. W. (2015). Evaluations of validity and reliability of a transtheoretical model for sedentary behavior among college students. American Journal of Health Behavior, 39(5), 601-609. doi: 10.5993/AJHB.39.5.2

Helfert, S., \& Warschburger, P. (2011). A prospective study on the impact of peer and parental pressure on body dissatisfaction in adolescent girls and boys. Body Image, 8(2), 101-109. doi: http://dx.doi.org/10.1016/j.bodyim.2011.01.004

Instituto Brasileiro de Geografia e Estatística. (2010). Pesquisa de Orçamentos Familiares (POF). Antropometria e estado nutricional de crianças, adolescentes e adultos no Brasil. 2008-2009 [Anthropometry and nutritional status of Brazilian children, adolescents and adults]. Rio de Janeiro: Author. Retrieved from http://biblioteca. ibge.gov.br/visualizacao/livros/liv45419.pdf.

Kuschnir, M. C. C., Bloch, K. V., Klein, C. H., Szklo, M., Klein, C. H., Barufaldi, L. A., ...Goldberg, T. B. L. (2016). ERICA: Prevalência de síndrome metabólica em adolescentes brasileiros. Revista de Saúde Pública, 50(1), 11. doi: 10.1590/ S01518-8787.2016050006701 
Ludwig, M. W. B. (2012). Modelo Transteórico de Mudança de comportamento na síndrome metabólica: Intervenções e fatores preditivos de mudança (Doctoral dissertation). Retrieved from http://hdl.handle.net/10923/5040

Ministério da Saúde, Secretaria de Atenção à Saúde, Departamento de Atenção Básica. (2014). Estratégias para o cuidado da pessoa com doença crônica: Obesidade. Retrieved from http://dab.saude.gov.br/portaldab/biblioteca. php? conteudo $=$ publicacoes $/$ cab38

Mostafavi, F., Ghofranipour, F., Feizi, A., \& Pirzadeh, A. (2015). Improving physical activity and metabolic syndrome indicators in women: A transtheoretical model-based intervention. International Journal of Prevention Medicine, 6(28). doi: 10.4103/2008-7802.154382

Prochaska, J. O., \& DiClemente, C. C. (1983). Stages and processes of self-change of smoking: Toward an integrative model of change. Journal of Consulting and Clinical Psychology, 51(3), 390395. doi: 10.1037//0022-006X.51.3.390

Prochaska, J. O., DiClemente, C. C., \& Norcross, J. C. (1992). In search of how people change. Applications to addictive behaviors. American Psychology, 47(9), 1102-1114. doi: 10.3109/10884609309149692

Prochaska, J. O., Norcross, J. C., Fowler, J. L., Follick, M. J., \& Abrams, D. B. (1992). Attendance and outcome in a work site weight control program: Processes and stages of change as process and predictor variables. Addiction Behavior, 17(1), 35-45. doi: 10.1016/0306-4603(92)90051-V

Queiroz de Medeiros, A. C., Pedrosa, L. F., \& Yamamoto, M. E. (2016). Food cravings among Brazilian population. Appetite, 108, 212-218. doi: 10.1016/j.appet.2016.10.009

Ribeiro, F. A., Boff, R. M., Feoli, A, M. P., Gustavo, A. S., Donadio, M. V., \& Oliveira, M. S. (2016). Randomized clinical trial of a motivational interdisciplinary intervention based on the transtheoretical model of change for lifestyle modification in overweight/obese adolescents: MERC study protocol. International Journal of Clinical Trials, 3(4), 225-232. doi: 10.18203/2349-3259. ijct20163961
Simmonds, M., Llewellyn, A., Owen, C. G., \& Woolacott, N. (2016). Predicting adult obesity from childhood obesity: A systematic review and meta-analysis. Obesity Review, 17(2), 95107. doi: 10.1111/obr.12334

Sousa, P., Gaspar, P., Fonseca, H., \& Gaspar, F. (2016). Lifestyle and treatment adherence among overweight adolescents. Journal of Health Psychology, 21(4), 562-572. doi: $10.1177 / 1359105314531469$

Spear, B. A., Barlow, S. E., Ervin, C., Ludwig, D. S., Saelens, B. E., Schetzina, K. E., \& Taveras, E. M. (2007). Recommendations for treatment of child and adolescent overweight and obesity. Pediatrics, 120(4), 254-288. doi: 10.1542/ peds.2007-2329F

Temple, J. L. (2016). Behavioral sensitization of the reinforcing value of food: What food and drugs have in common. Preventive Medicine, 92, 9099. doi: 10.1016/j.ypmed.2016.06.022

Velasquez, M. M., Mauer, G. G., Crouch, C., \& DiClemente, C. C. (2001). Group treatment for substance abuse: A stages-of- change therapy manual. New York: The Guilford Press.

Velicer, W. F., DiClemente, C. C., Rossi, J. S., \& Prochaska, J. O. (1990). Relapse situations and self-efficacy: An integrative model. Addictive Behaviors, 15(3), 271-283. doi: 10.1016/03064603(90)90070-E

World Health Organization. (2000). Obesity: preventing and managing the global epidemic (Report of a World Health Organization Consultation). Geneva: Author.

World Health Organization. (2016). Childhood overweight and obesity. Retrieved from http://www. who.int/dietphysicalactivity/childhood/en/

World Obesity Federation. (2016). Childhood Obesity. Retrieved from http://www.worldobesity. org/resources/child-obesity/

Recebido: 15/03/2017

$1^{a}$ revisão: $30 / 05 / 2017$

Aceite final: $28 / 06 / 2017$

(cc)BY The Author(s), 2018. Open Access. This article is distributed under the terms of the Creative Commons Attribution 4.0 International License (http://creativecommons.org/licenses/by/4.0/), which permits unrestricted use, distribution, and reproduction in any medium, provided you give appropriate credit to the original author(s) and the source, provide a link to the Creative Commons license, and indicate if changes were made. 